\section{A History of Lubricants}

In a civilization that depends on machines, materials that lubricate moving parts are absolutely essential. A "lubricant" is any substance placed between surfaces to decrease friction and wear, though lubricants can also act as coolants, cleansing agents, electrical insulators, and rust preventives.

Primitive man probably noticed how much easier it was to haul logs that had been stripped of bark because of the lubrication provided by sap oozing from the wood. Other prehistoric lubricants were mud or crushed reeds placed under dragged sledges for hauling game or timbers and rocks for building construction.

More extensive use of lubrication was required with the invention of the wheel and axle. The first carts were made with crude wooden axles and bearings. Eventually, people discovered that smearing a lump of animal fat on the dry and squeaking parts made the wheel run quietly and smoothly. However, without the scientific concept of friction, no one knew why.

When iron and brass replaced wood as moving parts in machinery, crude lumps of animal fat proved to be inadequate lubricants. The second generation of fatty and oily substances were derived from animal oils, vegetable oils, or a mixture of the two. Some of these lubricants-tallow, olive oil, castor oil, peanut oil, and rape oil-are still used for specialized purposes. After about the 16th century, whale oil and porpoise oil came into wide use.

With the rise of the petroleum industry in the 19th century, petroleum-based lubricants quickly dominated the field. Petroleum itself had been known long before this-since the ancient Assyrians and Egyptians, who used it for lighting and embalming. American Indians used crude petroleum medicinally. The American colonists who discovered petroleum while drilling for salt considered it a nuisance and poured it away as waste.

One of the earliest references to crude oil used as a lubricant is from a cotton spinning mill in Pittsburgh, Pennsylvania, in 1845. The owner apparently tried a sample of mineral oil obtained from a salt well drilled on the Allegheny River. Mineral oils, derived from crude petroleum, consist of a complex mixture of saturated and unsaturated aliphatic and aromatic hydrocarbons.

The Pittsburgh cotton-mill owner experimented with his mineral oil by mixing it with the sperm oil he had been using to

lubricate his spindles. He found the lubricant blend to be much more satisfactory than the straight sperm oil and continued to use the new lubricant for 10 years, while keeping it a secret from his competitors. Fifteen years later, when Colonel Edwin L. Drake drilled the first actual oil well, petroleum lubricants began replacing nonmineral materials throughout industry.
In a civilization that depends on machines, materials that lubricate moving parts are absolutely essential.

Petroleum lubricants, like their animal and vegetable oil predecessors, are liquids. Liquid lubricants have an advantage over semisolid lubricants (such as grease and animal fat) in that they can be drawn between moving parts by hydraulic action. The most important material property of liquid lubricants is their viscosity, or their ability to resist flow. Various methods of refining petroleum byproducts created lubricants with different ratings of viscosity.

Since early machines were relatively simple, lubricants more sophisticated than simple crude oil were unnecessary. Most industrial shops kept a barrel of oil in the corner for refilling cans used to squirt oil into the machines. Some employee would get the messy job of dribbling oil into all bearings, using the same type of lubricant for each moving part, no matter what its purpose.

The development of larger machines used at greater speeds and with tighter specifications for mass production led to specialization in lubricating materials. A general-purpose oil that worked well enough on a simple machine could not meet the new requirements for higher temperatures and speeds. Operational failures that could be traced directly to friction and wear became more and more frequent.

Better lubricants, special additives, and automatic dispensing systems have been major advances in the science of lubrication. Applications for automobiles, airplanes, turbojets, diesel locomotives, and high-power machinery have led to specialized lubricants.

Since the 1950s, synthetic liquid lubri- cants with lower volatility, better hightemperature performance, and greater fire resistance have been developed for naval craft, missiles, and other weapons. The raw materials for these synthetically prepared neutral substances are plasticizers, resin polymers, and organic solvents. The most common synthetic liquid lubricants frequently used in aircraft turbines are dibasic acid esters, which have low freezing points and excellent viscosity-temperature properties, retaining their viscocity over wide temperature ranges.

Silicone polymers, too, have superior viscosity-temperature properties and are used for lubrication at high temperatures. While fluorinated and chlorinated compounds do not have good viscositytemperature characteristics, they can be used in the presence of reactive compounds. Fluorinated silicones combine the best properties of fluorinated hydrocarbons and silicones. Other synthetic lubricants include polyethylene glycols and their derivatives, and also phosphate esters.

Modern semisolid lubricants, such as grease, consist of thickening agents in a mineral oil or synthetic liquid base. Vegetable and animal fats, resins, gels, waxes, fatty acids, saponified fats, and naphthalenic acids can be used as thickening agents; the most common are metallic soaps made with calcium, barium, sodium, or lithium. For some applications, greases have a base made of synthetic liquid, such as fluorocarbon liquid or silicone liquid.

When the operating conditions of temperature and pressure are too severe for liquids or semisolids, solid lubricating materials can be used. In rocket-propelled devices, the lubricant actually comes into contact with oxidants and reactive fuels. Unfortunately, solid lubricants usually lack good adhesive properties, requiring the use of binder materials to bond the lubricant to the surfaces of the moving parts. The most common powdered solid lubricants are graphite, tungsten disulfide, molybdenum disulfide, zinc oxide, and boron nitride. These materials can function as lubricants up to temperatures as high as $650^{\circ} \mathrm{C}$; with such properties, they are used in many hot metalworking operations.

Chemists, physicists, engineers, oil refiners, and metallurgists have all combined their expertise to develop new materials for lubrication that can withstand the most rigorous specifications for jet engines, space flight, and ultrafast processing, as well as new applications still being developed for industry and research.

Kevin J. Anderson 